\title{
Endoplasmic Reticulum Calcium Homeostasis in Kidney Disease
}

\section{Pathogenesis and Therapeutic Targets}

\author{
Sun-Ji Park, Chuang Li, and Ying Maggie Chen
}

From the Division of Nephrology, Department of Medicine, Washington University School of Medicine, St. Louis, Missouri

\author{
Accepted for publication \\ November 6, 2020. \\ Address correspondence to \\ Ying Maggie Chen, M.D., \\ Ph.D., Division of Nephrology, \\ Campus Box 8126, Washington \\ University School of Medicine, \\ St. Louis, MO 63110. E-mail: \\ ychen32@wustl.edu.
}

\begin{abstract}
Calcium $\left(\mathrm{Ca}^{2+}\right)$ homeostasis is a crucial determinant of cellular function and survival. Endoplasmic reticulum (ER) acts as the largest intracellular $\mathrm{Ca}^{2+}$ store that maintains $\mathrm{Ca}^{2+}$ homeostasis through the ER $\mathrm{Ca}^{2+}$ uptake pump, sarco/ER $\mathrm{Ca}^{2+}$ ATPase, ER $\mathrm{Ca}^{2+}$ release channels, inositol 1,4,5-trisphosphate receptor channel, ryanodine receptor, and $\mathrm{Ca}^{2+}$-binding proteins inside of the ER lumen. Alterations in ER homeostasis trigger $\mathrm{ER} \mathrm{Ca}^{2+}$ depletion and ER stress, which have been associated with the development of a variety of diseases. In addition, recent studies have highlighted the role of $\mathrm{ER} \mathrm{Ca}^{2+}$ imbalance caused by dysfunction of sarco/ER $\mathrm{Ca}^{2+}$ ATPase, ryanodine receptor, and inositol 1,4,5trisphosphate receptor channel in various kidney diseases. Despite progress in the understanding of the importance of these ER $\mathrm{Ca}^{2+}$ channels, pumps, and binding proteins in the pathogenesis of kidney disease, treatment is still lacking. This mini-review is focused on: i) $\mathrm{Ca}^{2+}$ homeostasis in the ER, ii) ER $\mathrm{Ca}^{2+}$ dyshomeostasis and apoptosis, and iii) altered $\mathrm{ER} \mathrm{Ca}^{2+}$ homeostasis in kidney disease, including podocytopathy, diabetic nephropathy, albuminuria, autosomal dominant polycystic kidney disease, and ischemia/reperfusion-induced acute kidney injury. (Am J Pathol 2021, 191: 256-265; https://doi.org/ 10.1016/j.ajpath.2020.11.006)
\end{abstract}

The endoplasmic reticulum (ER) is the main intracellular calcium $\left(\mathrm{Ca}^{2+}\right)$ store and plays an essential role in intracellular $\mathrm{Ca}^{2+}$-mediated cell signaling. ${ }^{1}$ Intracellular $\mathrm{Ca}^{2+}$ is a ubiquitous and versatile signaling molecule that controls many fundamental cellular processes, including proliferation, differentiation, secretion, metabolism, contraction, and cell death. ${ }^{2,3}$ Thus, the maintenance of ER $\mathrm{Ca}^{2+}$ homeostasis is crucial for cell function and survival.

The ER maintains intracellular $\mathrm{Ca}^{2+}$ homeostasis through the integrated and coordinated processes of $\mathrm{Ca}^{2+}$ uptake, release, and binding, which are controlled by an ERlocalized $\mathrm{Ca}^{2+}$ pump [sarco/ER $\mathrm{Ca}^{2+}$ ATPase (SERCA)], two $\mathrm{Ca}^{2+}$-release channels [inositol 1,4,5-trisphosphate receptor channel $\left(\mathrm{IP}_{3} \mathrm{R}\right)$ and ryanodine receptor $\left.(\mathrm{RyR})\right]^{4,5}$ and $\mathrm{Ca}^{2+}$-binding proteins, respectively. The lumen of the ER has a greater $\mathrm{Ca}^{2+}$ concentration than does the cytosol. ${ }^{6}$ The
Y.M.C. is supported by NIH grants R01 DK105056, R03DK106451 and K08DK089015; Office of the Assistant Secretary of Defense for Health Affairs Peer Reviewed Medical Research Program Award W81XWH-19-10320; George M. O’Brien Kidney Research Core Center NU GoKidney NIH grant P30 DK114857; Mallinckrodt Challenge Grant; Washington University Center for Drug Discovery Investigator Matching Micro Grant; Washington University Children's Discovery Institute and St. Louis Children's Hospital Faculty Scholar Award MD-FR-2013-336; and Doris Duke Charitable Foundation Clinical Scientist Development Award 2015100. Y.M.C. is a member of the Washington University Diabetes Research Center, supported by NIH grant P30 DK020579; the Washington University Musculoskeletal Research Center, supported by NIH grant P30AR057235; and the Washington University Institute of Clinical and Translational Sciences, supported by grant UL1 TR000448.

Disclosures: Patent application "Compositions and Methods for Treating and Preventing Endoplasmic Reticulum (ER) Stress-Mediated Kidney Diseases" has been filed by Y.M.C., S.-J.P., Y.K., F.U. and the Washington University Office of Technology Management (serial number 62/686705, filed in June 2018). 
$\mathrm{Ca}^{2+}$ stored in the ER lumen is essential for the regulation of protein post-translational modification, folding, and transport. ER $\mathrm{Ca}^{2+}$ released to the cytosol provides sustained and precise $\mathrm{Ca}^{2+}$-mediated cellular responses, ${ }^{3,4}$ the dysregulation of which may lead to cell death.

Alterations in ER $\mathrm{Ca}^{2+}$ homeostasis result in the accumulation of unfolded proteins, which in turn causes ER stress and activates the unfolded-protein response. ${ }^{4}$ Depending on the duration and severity of the stress, activation of the unfolded protein response can lead to either cell survival or cell death. The unfolded-protein response triggers an adaptive response, through the activation of activating transcription factor 6, protein kinase RNA-like ER kinase (PERK), or inositolrequiring enzyme (IRE)-1 signaling pathway, to relieve stress and restore ER function. ${ }^{7}$ However, if ER stress is too severe or prolonged, the unfolded-protein response switches to proapoptotic pathways through the activation of CCAAT/enhancerbinding protein homologous protein (CHOP), Jun N-terminal kinase (JNK), or caspase 12. In addition, $\mathrm{ER} \mathrm{Ca}^{2+}$ depletion can induce a subsequent increase in cytosolic $\mathrm{Ca}^{2+}$, which in turn activates cytosolic $\mathrm{Ca}^{2+}$-dependent cysteine proteases (calpains), which cleave ER-resident procaspase 12, leading to the activation of caspase cascades and, ultimately, cellular dysfunction and cell death. ${ }^{8}$

Disturbances in $\mathrm{ER} \mathrm{Ca}^{2+}$ homeostasis contribute to the pathophysiology of various diseases, including diabetes mellitus, neurologic disorders, cancer, and kidney disease. $^{2-4,6}$ The present review discusses the molecular mechanisms underlying $\mathrm{Ca}^{2+}$ dyshomeostasis-mediated kidney disease, with a focus on $\mathrm{ER} \mathrm{Ca}^{2+}$ pumps, receptor channels, and $\mathrm{Ca}^{2+}$-binding proteins.

\section{$\mathrm{Ca}^{2+}$ Homeostasis in the ER}

Intracellular free $\mathrm{Ca}^{2+}$ concentration varies widely depending on its location. Cytosolic $\mathrm{Ca}^{2+}$ concentration is maintained at low levels (10 to $100 \mathrm{nmol} / \mathrm{L}$ ) against a high (10,000-fold) $\mathrm{Ca}^{2+}$ concentration in the ER and in the extracellular milieu. ${ }^{4,9}$ Inside of the cell, $\mathrm{Ca}^{2+}$ levels in the nuclear matrix and in the mitochondria matrix are similar to that in the cytosol. ${ }^{9}$ The largest intracellular $\mathrm{Ca}^{2+}$ store is the ER that can accumulate $\mathrm{Ca}^{2+}$ and maintain a high $\mathrm{Ca}^{2+}$ concentration $(100$ to $500 \mu \mathrm{mol} / \mathrm{L})$. The $\mathrm{Ca}^{2+}$ gradient is conserved between different intracellular organelles and the cytosol, which facilitates a variety of $\mathrm{Ca}^{2+}$-mediated cell signaling. ${ }^{3}$ The tight regulation of ER and cytosolic $\mathrm{Ca}^{2+}$ levels is achieved by the orchestrated action of $\mathrm{Ca}^{2+}$ pumps, channels, and $\mathrm{Ca}^{2+}$-binding ER luminal proteins, which are located in the ER membrane, ER lumen, and ER-mitochondrial contact sites ${ }^{3,4}$ (Figure 1).

\section{ER Calcium Uptake Pump SERCA}

$\mathrm{Ca}^{2+}$ uptake into the ER from the cytosol is mainly driven by SERCA pumps. The SERCA pumps are integral transmembrane proteins of the ER that consume the energy of ATP to drive $\mathrm{Ca}^{2+}$ across the membrane against electrochemical gradient. ${ }^{5}$ The SERCA pumps are encoded by a family of three genes (SERCA1 to SERCA3) with different expression and $\mathrm{Ca}^{2+}$ affinities in a cell-specific manner., ${ }^{2,3}$ SERCA1 is expressed in skeletal muscles, and SERCA2a is expressed in cardiac and skeletal muscles, while SER$\mathrm{CA} 2 \mathrm{~b}$ and SERCA3 are present in nonmuscle tissues. ${ }^{10}$ The function of the SERCA pump is modulated by membrane proteins phospholamban (PLN) and sarcolipin. ${ }^{3,10}$ The phosphorylated form of PLN activates cardiac SERCA pump through a $\beta$-adrenergic response by either protein kinase (PK) A or calmodulin-dependent kinase (CaMK) II, whereas the dephosphorylated form of PLN inhibits SERCA activity. ${ }^{5,10}$ A similar regulation of the SERCA pump in skeletal muscle is accomplished by sarcolipin. ${ }^{5}$ SERCA activity is regulated by certain ER luminal chaperones such as calnexin (CNX) and calreticulin (CRT). ${ }^{3,11,12}$ When the $\mathrm{Ca}^{2+}$ store in the ER is full, CNX and CRT physically interact with SERCA2b and inhibit its activity, thereby controlling $\mathrm{Ca}^{2+}$ homeostasis. ${ }^{11,12}$ It has been shown that overexpression of CRT promotes inactivation and degradation of SERCA2a in oxidative stress, leading to an alteration in $\mathrm{Ca}^{2+}$ homeostasis and enhanced susceptibility to apoptosis. ${ }^{12}$

\section{ER Calcium-Release Channels $\mathrm{IP}_{3} \mathrm{R}$ and RyR}

$\mathrm{Ca}^{2+}$ release from the lumen of the ER into the cytosol is mediated mainly by $\mathrm{IP}_{3} \mathrm{R}$ and RyR channels localized on the ER membrane. ${ }^{3,4}$ Both channels exist in three isoforms $\left(\mathrm{IP}_{3} \mathrm{Rs} 1\right.$ to 3 and RyRs 1 to 3 ), which are assembled to produce large hetero- and homotetrameric $\mathrm{Ca}^{2+}$-release channels. IP ${ }_{3} \mathrm{R}$ and RyR channels have different $\mathrm{Ca}^{2+}$ affinities and are expressed in distinct tissues. ${ }^{2,3} \mathrm{IP}_{3} \mathrm{R}$ channels are ubiquitously expressed in most cell types. ${ }^{13} \mathrm{IP}_{3} \mathrm{R}$ channels are activated by $\mathrm{IP}_{3}$ that is produced when phospholipase (PL) C hydrolyzes phosphatidylinositol-4,5bisphosphate $\left(\mathrm{PIP}_{2}\right){ }^{13,14}$ Binding of a ligand or other agonists to a G-protein-coupled receptor results in G-protein-subunit activation, which in turn triggers PLCmediated cleavage of $\mathrm{PIP}_{2}$ to $\mathrm{IP}_{3}$ and diacylglycerol. ${ }^{4,14}$ The $\mathrm{IP}_{3}$ acts as an intracellular messenger and binds to $\mathrm{IP}_{3} \mathrm{R}$, stimulating $\mathrm{Ca}^{2+}$ release from the ER to the cytosol. ${ }^{2,4}$ $\mathrm{Ca}^{2+}$ release by $\mathrm{IP}_{3} \mathrm{R}$ is inhibited by ER resident protein (ERp)-44 (depending on $\mathrm{pH}$ ), ER $\mathrm{Ca}^{2+}$ concentration, and redox state. ERp44, a novel ER luminal oxidoreductase of the thioredoxin family, senses the environment in the ER lumen and inhibits $\mathrm{IP}_{3} \mathrm{R} 1$ activity through direct interaction with the ER luminal domain of $\mathrm{IP}_{3} \mathrm{R} 1 .{ }^{15}$ Numerous modulatory proteins have been shown to bind to $\mathrm{IP}_{3} \mathrm{R}$ and modulate its function, including $\mathrm{IP}_{3} \mathrm{R}$-binding protein released with $\mathrm{IP}_{3}$, calmodulin, and caldendrin. 5,14

RyR is a member of the same gene family as $I_{3} R$, and there is approximately $40 \%$ homology between RyR and $\mathrm{IP}_{3} \mathrm{R}$ in their putative transmembrane regions. ${ }^{14}$ Although 
structurally related, RyRs and $\mathrm{IP}_{3} \mathrm{Rs}$ have distinct physiologic profiles. The RyR family has three isoforms: i) RyR1 in skeletal muscle, ii) RyR2 in heart, and iii) RyR3 in brain. Recently, these isoforms have also been found in other tissues. ${ }^{5,16}$ Although the expression level of RyR is much lower than that of $\mathrm{IP}_{3} \mathrm{R}$ in most cell types, the role of RyR is important; the opening of RyR releases about 20-fold more $\mathrm{Ca}^{2+}$ ions than does that of $\mathrm{IP}_{3} \mathrm{R} .{ }^{13}$ In addition, RyR has high-affinity $\mathrm{Ca}^{2+}$-binding sites involved in triggering $\mathrm{Ca}^{2+}$-induced $\mathrm{Ca}^{2+}$ release to the cytosol. ${ }^{17,18}$ The open probability of RyR depends on the cytosolic $\mathrm{Ca}^{2+}$ concentration; RyR is normally closed at low cytosolic $\mathrm{Ca}^{2+}$ levels (approximately 100 to $200 \mathrm{nmol} / \mathrm{L}$ ), and opened at sub- $\mu \mathrm{M}$ cytosolic $\mathrm{Ca}^{2+}$ levels due to $\mathrm{Ca}^{2+}$ binding to high-affinity binding sites on RyR, which increases the open probability. The channel activity is maximal at a cytosolic $\mathrm{Ca}^{2+}$ concentration of approximately $10 \mu \mathrm{mol} / \mathrm{L}$, while elevated levels beyond this point lead to a reduction in open probability. ${ }^{14,18} \mathrm{Ca}^{2+}$ influx across cell membrane via the voltage-gated $\mathrm{L}$ (long lasting)-type $\mathrm{Ca}^{2+}$ channel (CaV1.2) activates RyR2 and triggers $\mathrm{Ca}^{2+}$-induced $\mathrm{Ca}^{2+}$ release, leading to myocyte contraction. ${ }^{16,18}$

RyR activity is modulated by phosphorylation and multiple binding proteins. $\beta$-Adrenoceptor stimulation leads to stimulatory G-protein-mediated activation of adenylyl cyclase (AC) and further cAMP-dependent activation of PKA. PKA can directly phosphorylate RyR1 at S2844 and RyR2 at S2808, causing reductions in the binding affinities to $\mathrm{Ca}^{2+}$ channel-stabilizing binding proteins (calstabins) 1 and 2, respectively. ${ }^{19,20}$ Calstabins stabilize the closed state of RyR channels and prevent excessive ER $\mathrm{Ca}^{2+}$ leak. ${ }^{14}$ Hyperphosphorylation of RyR2 S2808 by PKA results in a diastolic sarcoplasmic reticulum $\mathrm{Ca}^{2+}$ leak in cardiomyocytes that contributes to chronically decreased sarcoplasmic reticulum $\mathrm{Ca}^{2+}$ contents and progressive cardiac dysfunction. ${ }^{20}$ Recently, it was also found that ERstressed podocytes undergo phosphorylation at S2808, causing leaky RyR2 and podocyte apoptosis. ${ }^{21}$ On the other hand, increased cytosolic $\mathrm{Ca}^{2+}$ levels activate CaMK II, which directly phosphorylates RyR2 at S2814 and increases

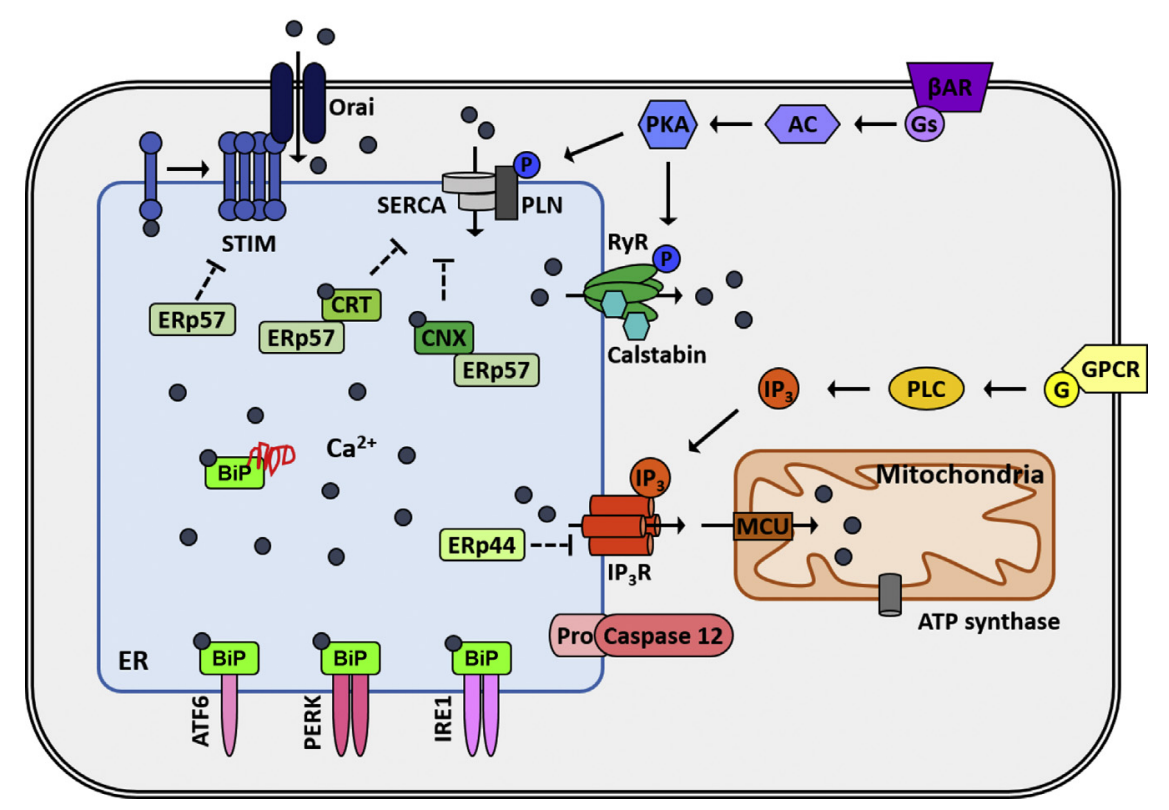

Figure 1 ER $\mathrm{Ca}^{2+}$ dynamics and homeostasis. $\mathrm{ER} \mathrm{Ca}^{2+}$ homeostasis is controlled by the orchestrated action of SERCA, IP ${ }_{3} \mathrm{R}$, RyR, and $\mathrm{Ca}^{2+}$. regulating proteins. $\mathrm{Ca}^{2+}$ uptake into the ER from the cytosol is mainly driven by SERCA. Phosphorylation of phospholamban (PLN) activates SERCA through stimulation of the $\beta$-adrenergic receptor $(A R) /$ protein kinase (PK)-A signaling pathway. When the $\mathrm{Ca}^{2+}$ stores in the ER are full, calnexin (CNX) and CRT reduce the activity of SERCA. Meanwhile, $\mathrm{Ca}^{2+}$ release from the lumen of the ER into the cytosol is mediated mainly by $\mathrm{IP}_{3} R$ and RyR. IP ${ }_{3} R$ is activated by binding of $I P_{3}$ that is produced through $\mathrm{G}$ protein-coupled receptor (GPCR)-mediated activation of PLC. $\mathrm{IP}_{3} \mathrm{R}$ is inhibited by ER resident protein ERp44, depending on $\mathrm{ER} \mathrm{Ca}^{2+}$ concentration. RyR activity is modulated by phosphorylation of serine and calstabin binding. PKA activation via $\beta-A R$ stimulation directly phosphorylates RyR and increases its activity, inducing dissociation from calstabins. Once $\mathrm{Ca}^{2+}$ is depleted in the ER lumen, dissociation of $\mathrm{Ca}^{2+}$ from the STIM proteins leads to STIM oligomerization and interaction with the plasma membrane $\mathrm{Ca}^{2+}$ release-activated $\mathrm{Ca}^{2+}$ channel protein (Orai) to increase $\mathrm{Ca}^{2+}$ influx from the extracellular milieu. SERCA colocalizes with STIM -Orai complex and pumps $\mathrm{Ca}^{2+}$ directly from the cytosol to allow ER $\mathrm{Ca}^{2+}$ store refilling. ERp57 interacts with CNX, CRT, and STIM, regulating SERCA activity and SOCE. Furthermore, $\mathrm{Ca}^{2+}$ store in the ER is closely associated with ER protein homeostasis. Alteration in ER homeostasis activates unfolded protein response through three ER stress sensors [inositol-requiring enzyme (IRE)-1, protein kinase RNA-like ER kinase (PERK), and activating transcription factor (ATF)-6] that are inactive and bound to $\mathrm{BiP}$ in the absence of stress. $A C$, adenylyl cyclase; ATF, activating transcription factor; Gs, stimulatory G-protein; MCU, mitochondrial $\mathrm{Ca}^{2+}$ uniporter. 
open probability of RyR2, not via calstabin 2 dissociation. ${ }^{22}$ Other regulatory proteins, such as calmodulin, calsequestrin, triadin, and junctin, interact with RyR and regulate its function. ${ }^{14,16}$

\section{ER Calcium Refill}

ER $\mathrm{Ca}^{2+}$ depletion promotes the entry of $\mathrm{Ca}^{2+}$ from the extracellular space into the cell to refill intracellular $\mathrm{Ca}^{2+}$ stores. This process is known as capacitive or store-operated $\mathrm{Ca}^{2+}$ entry (SOCE) and is activated by the ER sensor, stromal-interacting molecule (STIM)., ${ }^{2,3}$ Two homologous STIMs, 1 and 2, are ER-resident proteins containing a single transmembrane domain and two EF-hand domains for sensing ER $\mathrm{Ca}^{2+}$ depletion. ${ }^{5}$ After $\mathrm{Ca}^{2+}$ is dissociated from the EF-hand domains of the STIM proteins, STIM oligomerizes and interacts with the plasma membrane channel, $\mathrm{Ca}^{2+}$ release-activated $\mathrm{Ca}^{2+}$ channel protein (Orai), to open $\mathrm{Ca}^{2+}$ entry from the extracellular milieu to the cytosol. ${ }^{2,4,5} \mathrm{In}$ turn, SERCA co-localizes with the STIM-Orai complex, which allows $\mathrm{Ca}^{2+}$ to be pumped directly from the cytosol into the ER lumen to replenish the deficit. ${ }^{23}$

\section{ER $\mathrm{Ca}^{2+}$-Binding Proteins}

In the $\mathrm{ER}, \mathrm{Ca}^{2+}$ is bound to luminal proteins, the most abundant of which are CRT and calsequestrin. CRT predominates in nonmuscle cells, whereas calsequestrin is more restricted to the muscle cells. In addition to these $\mathrm{ER} \mathrm{Ca}^{2+}$ storage proteins, there are a number of $\mathrm{Ca}^{2+}$-binding molecular chaperones. These include CNX, CRT, Ig-binding protein/78-kDa glucose-regulated protein (BiP/GRP78), and GRP94. A third class of $\mathrm{Ca}^{2+}$-binding proteins includes several oxidoreductases in the ER lumen, which comprise protein disulfide isomerases (PDIs), ERp44 and ERp57 (also known as PDI3), as well as ER oxidoreductin 1.,4,24 These molecular chaperones and folding enzymes can not only buffer ER free $\mathrm{Ca}^{2+}$ molecules, but also catalyze protein folding and processing.

Moreover, some of these proteins are involved in the regulation of the activities of $\mathrm{Ca}^{2+}$ pumps and channels, which contribute to the maintenance of a high free $\mathrm{Ca}^{2+}$ environment in the ER lumen. ${ }^{3}$ The ER luminal ERp57, a glycoprotein-specific thiol-disulfide oxidoreductase, can inhibit SOCE by interacting with the ER luminal domain of STIM1 ${ }^{25}$. ERp57 also interacts with CNX and CRT to modulate the activity of SERCA2b. Taken together, the integration of these $\mathrm{Ca}^{2+}$-handling proteins is essential for the control of steady-state ER luminal $\mathrm{Ca}^{2+}$ levels, which contribute to the maintenance of intracellular ER $\mathrm{Ca}^{2+}$ homeostasis.

\section{ER $\mathrm{Ca}^{2+}$ Dyshomeostasis and Apoptosis}

ER $\mathrm{Ca}^{2+}$ homeostasis critically controls cell survival and cell death. ${ }^{1-4,26,27}$ Physiologic $\mathrm{Ca}^{2+}$ release from the ER induces $\mathrm{Ca}^{2+}$ uptake by mitochondria, which in turn results in increased mitochondrial respiration and ATP production, enhancing mitochondrial bioenergetics and regulating cell survival. ${ }^{26}$ The subsequent reduction in ER luminal $\mathrm{Ca}^{2+}$ is restored via SOCE and mediated by the STIM-Orai complex and the activation of SERCA. ${ }^{3}$ In contrast, pathologic conditions may cause an imbalance between ER $\mathrm{Ca}^{2+}$ release and uptake mechanisms (Figure 2). Impaired functioning of mitochondrial uptake, SOCE, or SERCA; increased activity of $\mathrm{IP}_{3} \mathrm{R}$ or RyR; or altered modulation by $\mathrm{Ca}^{2+}$-regulating proteins may contribute to both decreased ER $\mathrm{Ca}^{2+}$ and increased mitochondrial and cytosolic $\mathrm{Ca}^{2+}$, thus failing to maintain normal ER luminal $\mathrm{Ca}^{2+}$ levels. ${ }^{2-4}$ The reduced ER luminal $\mathrm{Ca}^{2+}$ can immediately provoke ER stress and apoptosis by disrupted $\mathrm{Ca}^{2+}$-dependent chaperone function and subsequent accumulation of unfolded proteins in the ER. ${ }^{28}$ The increased mitochondrial and cytosolic $\mathrm{Ca}^{2+}$ influx may augment apoptotic cell death through the activation of $\mathrm{Ca}^{2+}$-dependent mitochondrial permeability transition pore and enzymes, such as CaMK II and calpain. ${ }^{1,4,26,27,29}$

\section{Calcium Dysregulation and ER-Mitochondria Crosstalk}

Regulated transfer of $\mathrm{Ca}^{2+}$ from the ER to mitochondria occurs through the opening of the $\mathrm{IP}_{3} \mathrm{R}$ on the ER membrane and the mitochondrial $\mathrm{Ca}^{2+}$ uniporter complex on the inner mitochondrial membrane. Excessive $\mathrm{Ca}^{2+}$ release from the ER can accumulate in the mitochondria. ${ }^{27}$ Mitochondrial $\mathrm{Ca}^{2+}$ overload increases the production of reactive oxygen species and the opening of the mitochondrial permeability transition pore. The permeability transition pore opening causes mitochondrial swelling, collapse of mitochondrial membrane potential, rupture of the outer mitochondrial membrane, and subsequent release of proapoptotic factor cytochrome $c .^{1,4,26,27,29}$ Cytochrome $c$ released into the cytosol binds to apoptosis-activating factor 1 to form the apoptosome complex, which can then recruit and activate the initiator caspase, caspase 9, and its downstream effector caspases, triggering apoptosis. ${ }^{26,27,29}$ Furthermore, sarcoplasmic reticulum $\mathrm{Ca}^{2+}$ leak via RyR2 triggers mitochondrial $\mathrm{Ca}^{2+}$ overload and increases reactive oxygen species production, which in turn further oxidizes RyR2 and enhances sarcoplasmic reticulum $\mathrm{Ca}^{2+}$ efflux, thereby contributing to heart failure after myocardial infarction. ${ }^{30}$

\section{Cytosolic $\mathrm{Ca}^{2+}$ Signaling and CaMK II}

Increased cytosolic $\mathrm{Ca}^{2+}$ activates CaMK II, which promotes inflammation and apoptosis. ${ }^{4,31}$ In toxicant-treated bone-marrow $\mathrm{B}$ cells, CaMK II is activated by $\mathrm{IP}_{3} \mathrm{R}$-mediated $\mathrm{Ca}^{2+}$ release, leading to p38 and JNK phosphorylation $^{4,32}$ and the subsequent induction of intrinsic apoptosis, accompanied by a loss of mitochondrial membrane potential, the release of cytochrome $c$, and the activation of caspase $3 .^{33}$ In cholesterol-loaded macrophages, CaMK II, 


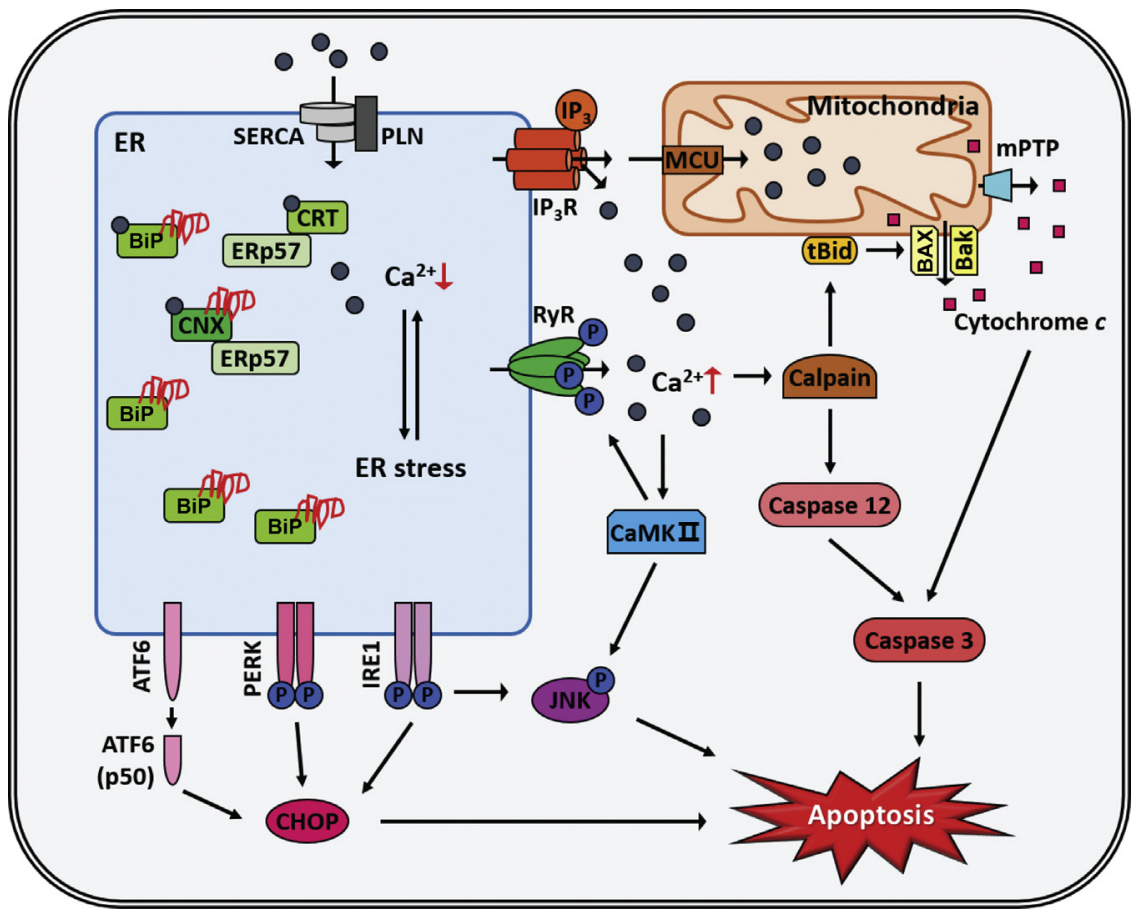

Figure $2 \mathrm{ER} \mathrm{Ca}^{2+}$ dysregulation and apoptosis. Enhanced chronic ER $\mathrm{Ca}^{2+}$ release elevates mitochondrial and cytosol $\mathrm{Ca}^{2+}$, which causes apoptosis through dysfunction of mitochondrial permeability transition pore (mPTP), CaMK II and calpain. Increased mitochondrial PTP opening results in mitochondrial cytochrome $c$ release. CaMK II activation stimulates RyR phosphorylation and the Jun $\mathrm{N}$-terminal kinase (JNK)-induced apoptotic pathway. Calpain activation cleaves truncated Bcell lymphoma 2 homology 3 -interacting domain death agonist (tBid) and caspase 12, mediating apoptosis. Moreover, excessive ER $\mathrm{Ca}^{2+}$ depletion results in accumulation of misfolded proteins, which triggers ER stress-induced apoptosis through activation of CCAAT/enhancer-binding protein homologous protein (CHOP), JNK, and caspase12. ER stress and increased ER $\mathrm{Ca}^{2+}$ efflux can amplify each other. ATF, activating transcription factor; BAK, B-cell lymphoma 2 homologous antagonist/killer; CNX, calnexin; IRE, inositolrequiring enzyme; $\mathrm{MCU}$, mitochondrial $\mathrm{Ca}^{2+}$ uniporter; PERK, protein kinase RNA-like ER kinase; PLN, phospholamban.

which is activated by accelerated ER to cytosol $\mathrm{Ca}^{2+}$ leakage, enables ER stress-induced apoptosis through the activation of the JNK-induced Fas apoptotic pathway and the promotion of mitochondrial $\mathrm{Ca}^{2+}$ uptake, followed by mitochondrial membrane permeabilization. ${ }^{34}$ Moreover, activated CaMK II in cardiomyocytes after ischemia/reperfusion (I/R) injury results in NF- $\kappa \mathrm{B}$ activation, elevated inflammatory response, and apoptosis. ${ }^{31}$ Sustained, excessive CaMK II activation is also implicated in obesity, advanced atherosclerotic lesions, and myocardial hypertrophy. ${ }^{4,31-34}$

\section{Cytosolic $\mathrm{Ca}^{2+}$ Signaling and Calpain}

Cytosolic $\mathrm{Ca}^{2+}$ elevation can also activate calpain by an autocatalytic cleavage, leading to the activation of key downstream apoptotic factors, such as caspase 12 and truncated BH3-interacting domain death agonist (tBid). ${ }^{26,35}$ For instance, cadmium-mediated inhibition of SERCA disrupts ER $\mathrm{Ca}^{2+}$ homeostasis and causes apoptosis through the calpain-caspase 12 pathway. ${ }^{36}$ In addition, calpain induces the cleavage of tBid, which promotes the oligomerization of BAX and/or BAK, and the release of cytochrome $c,^{35}$ as occurs in cisplatin-treated melanoma cells. $^{37}$

\section{Altered ER $\mathrm{Ca}^{2+}$ Homeostasis in Kidney Disease}

The functional units of the kidneys are the nephrons, which filter the blood, reabsorb water and solutes, and secrete wastes to the urine to maintain body homeostasis.
Approximately 1 million nephrons are contained in the renal parenchyma, the functional portion of the kidney consisting of cortex and medulla. Each nephron is composed of a glomerulus and renal tubules, and the filtration barrier of the glomerulus is composed of glomerular endothelial cells, glomerular basement membrane, and podocytes. Each cell type contains a unique combination of $\mathrm{Ca}^{2+}$ pumps and channels to elicit the cell type-specific $\mathrm{Ca}^{2+}$ signaling

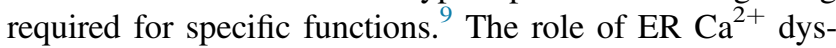
homeostasis in the pathogenesis of various kidney diseases is still not well understood. This review focuses on the role of dysfunctional ER $\mathrm{Ca}^{2+}$ channels, pumps, and $\mathrm{Ca}^{2+}$. handling proteins in the pathogenesis of a variety of kidney diseases, including podocytopathy, diabetic nephropathy, albuminuria, autosomal dominant polycystic kidney disease (ADPKD), and I/R-induced tubular injury. Also included are novel targeted therapies for the treatment of ER stress-induced kidney disease.

\section{Monogenic Podocytopathy and RyR2}

Familial focal segmental glomerulosclerosis and nephrotic syndrome are a primary podocytopathy caused by podocytespecific mutations in genes including NPHS1, NPHS2, WT1, LAMB2, CD2AP, TRPC6, ACTN4, and INF $2 .{ }^{38}$ Hereditary familial focal segmental glomerulosclerosis has drawn considerable attention recently due to the molecular insights into the disease pathogenesis. Laminin (LAM)- $\beta 2$, encoded by $L A M B 2$, is synthesized and secreted from both podocytes and glomerular endothelial cells, and is a major component of the mature glomerular basement membrane. $L A M B 2$ is 
also one of the most commonly mutated disease-causing genes, and C321R-LAMB2 missense mutation causes congenital nephrotic syndrome. ${ }^{39}$ Our study has shown that podocyte ER stress induced by C321R-LAMB2 mutation causes ER $\mathrm{Ca}^{2+}$ leak and cytosolic $\mathrm{Ca}^{2+}$ elevation through phosphorylation of RyR2 at Ser2808. ${ }^{21}$ The cytosolic $\mathrm{Ca}^{2+}$ overload accelerates calpain 2 activation and cleavage of its downstream apoptotic molecule procaspase 12 and podocyte cytoskeletal protein talin 1 , resulting in podocyte apoptosis and injury. Importantly, the ER $\mathrm{Ca}^{2+}$ stabilizer K201 can block RyR2 phosphorylation-mediated ER Ca ${ }^{2+}$ depletion and subsequent calpain 2-caspase 12 activation in the C321R-mutant podocytes, as well as mitigate albuminuria in the $\mathrm{Lamb2}^{-/-}$mice expressing the mutant C321R-Lamb2 in podocytes. In addition, mesencephalic astrocyte-derived neurotrophic factor, as a biotherapeutic ER protein, can fix leaky RyR2 and inhibit ER stress-induced podocyte injury. ${ }^{21}$

Gene mutations in transient receptor potential channel subfamily $\mathrm{C}$ member 6 (TRPCO) gene, the main $\mathrm{Ca}^{2+}$ permeable ion channel in the plasma membrane of nonexcitable cells, including podocytes, also cause inherited familial focal segmental glomerulosclerosis. R895C and E897K TRPC6 mutations enhance channel activity and elevate cytosolic $\mathrm{Ca}^{2+}$ levels, which can activate cytosolic phosphatase calcineurin, resulting in dephosphorylation and translocation of nuclear factor of activated $\mathrm{T}$ cells to the nucleus to activate calcineurin-dependent transcription. ${ }^{40}$ Podocyte nuclear factor of activated T-cell activation in mice reduces the expression of podocyte slit-diaphragm proteins, such as podocin, synaptopodin, and nephrin, and thus causes podocyte dysfunction and impairment of glomerular filtration barrier, eventually leading to progressive proteinuria and familial focal segmental glomerulosclerosis. Thus, $\mathrm{Ca}^{2+}$-regulated nuclear factor of activated $\mathrm{T}$-cell signaling in podocytes may be a key intermediate factor in the pathogenesis of TRPC6 mutation-induced familial focal segmental glomerulosclerosis. ${ }^{41}$

\section{Diabetic Nephropathy and SERCA}

Diabetic nephropathy is the most common cause of endstage renal disease worldwide. Convergent evidence reveals that SERCA2 activity and expression are diminished in islet, heart, and liver of animal models of diabetes, implying a potential pathologic role of SERCA2 dysfunction in the development of diabetic complications. ${ }^{42-44}$ In addition, significant reductions in SERCA2 activity and expression have been noted in the kidney cortex of $d b / d b$ mice, a mouse model of type 2 diabetes. ${ }^{45}$ The impaired activity and expression of SERCA2 caused ER $\mathrm{Ca}^{2+}$ depletion, which triggered ER stress and activation of ER stress- and mitochondria-mediated apoptotic pathways. Importantly, astragaloside (AS)-IV, a small molecular bioactive saponin isolated from Astragalus membranaceus, restored SERCA2 activity and expression, and suppressed aberrant ER
$\mathrm{Ca}^{2+}$-induced apoptosis in $d b / d b$ mouse kidneys. Moreover, AS-IV ameliorated albuminuria, glomerulosclerosis, and renal inflammation, as well as improved renal function through the up-regulation of SERCA2 function. ${ }^{45}$

\section{Albuminuria and ER $\mathrm{Ca}^{2+}$ Depletion}

When the permeability of glomerular capillary wall increases, macromolecules such as albumin leak into urinary space, leading to proteinuria. Proteinuria is a clinical marker and a potent predictor of the progression of chronic kidney disease. ${ }^{46}$ In addition, it is an active player in the development of chronic kidney disease. ${ }^{47}$ In podocytes, albumin can stimulate $\mathrm{Ca}^{2+}$ release from the ER $\mathrm{Ca}^{2+}$ store and $\mathrm{Ca}^{2+}$ influx through TRPC6, the overexpression of which has been noted in human proteinuric kidney disease. TRPC6mediated $\mathrm{Ca}^{2+}$ entry triggers ER stress-induced apoptosis and F-actin cytoskeleton disruption in podocytes. ${ }^{46}$ In tubular cells, it has been shown that albumin rapidly elevated cytosolic $\mathrm{Ca}^{2+}$ by triggering $\mathrm{Ca}^{2+}$ efflux from the $\mathrm{ER}$, which in turn activated SOCE to maintain the rise of cytosolic $\mathrm{Ca}^{2+} .{ }^{47}$ The albumin-induced $\mathrm{ER} \mathrm{Ca}^{2+}$ depletion up-regulated activating transcription factor 4-dependent lipocalin (LCN)-2 expression, which induced apoptosis by augmenting reactive oxygen species generation. ${ }^{47}$ Consistently, Lcn2 has also been remarkably increased in the renal tubules of proteinuric chronic kidney disease patients and proteinuric $W T 1^{+/ m u t}$ mice. Treatment with a chemical chaperone, 4-phenylbutyric acid, or Lcn2 deficiency, has been reported to alleviate ER stress-induced apoptosis and tubulointerstitial damage in $W T 1^{+/ \text {mut }}$ or acquired proteinuric nephropathy mice. Moreover, 4-phenylbutyric acid dramatically reduced urinary LCN2 excretion in proteinuric patients. $^{47}$

\section{ADPKD and Disturbed Polycystin-Mediated $\mathrm{Ca}^{2+}$ Signaling}

ADPKD is characterized by the formation and progressive enlargement of fluid-filled renal cysts that lead to end-stage renal disease in more than half of patients by the age of 60 years. Loss-of-function mutations in $P K D 1$ or $P K D 2$, which encode polycystins (PCs) 1 and 2, respectively, are the most common causes of ADPKD. ${ }^{48,49}$ PCs 1 and 2 form a heterodimeric complex through their $\mathrm{C}$-terminal regions in the plasma membrane, primary cilia, and ER membrane. $\mathrm{PC} 1$ is a large, 4302-amino acid transmembrane protein that serves as a sensor. PC2 is a 968-amino acid transmembrane protein primarily localized in the ER. Known as a member of the TRPC superfamily, PC2 is a nonselective cation channel. ${ }^{48}$ The co-assembly of PC1/PC2 mediates $\mathrm{Ca}^{2+}$ influx at the plasma membrane, ${ }^{50}$ and is involved in mechanosensation and flow-dependent $\mathrm{Ca}^{2+}$ signaling in the primary cilium. ${ }^{51}$ Furthermore, $\mathrm{PC} 1$ binds to $\mathrm{IP}_{3} \mathrm{R}$ and STIM1 in the ER. PC2 interacts with TRPC subfamily C member 1 in the primary cilium and plasma membrane, 
TRPC subfamily $\mathrm{V}$ member 4 in the cilia, as well as $\mathrm{IP}_{3} \mathrm{R}$ and RyR2 in the ER. Thus, PCs 1 and 2 also act as regulators of other $\mathrm{Ca}^{2+}$ channel proteins, ultimately modulating $\mathrm{Ca}^{2+}$ fluxes and ER $\mathrm{Ca}^{2+}$ stores. ${ }^{49}$

Disrupted $\mathrm{Ca}^{2+}$ homeostasis through aberrant functioning of polycystins is linked to the development of ADPKD, in which cyst-lining epithelial cells show increased rates of both proliferation and apoptosis. Loss of $\mathrm{PC} 1$ and $\mathrm{PC} 2$ function results in a decrease in cytosolic $\mathrm{Ca}^{2+}$, and an increase in cAMP levels via the activation of $\mathrm{Ca}^{2+}$-dependent AC, which activates PKA and stimulates its downstream Src/Ras/B-Raf/MEK/ERK pathway to promote the growth and proliferation of cystic cells. ${ }^{52,53}$ The compound deletion of both PC1 and AC6 in collecting duct attenuates PKD. ${ }^{54}$ Moreover, $\mathrm{Ca}^{2+}$ restriction affects PI3K/AKT, Wnt, and mechanistic target of rapamycin signaling to augment cystic cell proliferation.

$\mathrm{ER} \mathrm{Ca}^{2+}$ signaling regulated by polycystins plays a key role in the increased apoptosis in ADPKD. The disruption of PC1 function down-regulates the PI3K/AKT pathway. AKT can directly phosphorylate $\mathrm{IP}_{3} \mathrm{R} 1$ at $\mathrm{S} 2681$, thereby inhibiting its activity. ${ }^{55}$ Suppressed AKT activity in cystic cells relieves the inhibition of the $\mathrm{IP}_{3} \mathrm{R}$ and contributes to the increase in $\mathrm{IP}_{3^{-}}$ induced $\mathrm{Ca}^{2+}$ release. ${ }^{48,49,55}$ On the other side, $\mathrm{PC} 1$ expression stimulates PI3K/AKT, which enhances the interaction between $\mathrm{IP}_{3} \mathrm{R}$ and STIM1, thus inhibiting $\mathrm{IP}_{3}$-induced $\mathrm{Ca}^{2+}$ release. $\mathrm{PC} 1$ can also bind to $\mathrm{IP}_{3} \mathrm{R}$, mitigating $\mathrm{ER} \mathrm{Ca}^{2+}$ release, as well as bind to STIM1, sequestering it to the ER membrane. The dissociation of STIM1 from Orai in the plasma membrane inhibits SOCE. In contrast, the association of $\mathrm{PC} 2$ with $\mathrm{IP}_{3} \mathrm{R}$ prolongs $\mathrm{IP}_{3}$-induced $\mathrm{Ca}^{2+}$ release. Kidney epithelial cells overexpressing PC2 show markedly augmented ER $\mathrm{Ca}^{2+}$ release that is lost after C-terminal truncation or by the introduction of a disease-causing PKD2 missense mutation. ${ }^{50,56}$ Thus, PC1 or STIM1 competes with PC2 for binding to $\mathrm{IP}_{3} \mathrm{R}$, which may be involved in controlling intracellular $\mathrm{Ca}^{2+}$ homeostasis. ${ }^{49,57}$ Increased $\mathrm{IP}_{3}$-induced $\mathrm{Ca}^{2+}$ release, particularly at the contact sites of the ER and mitochondria, mitochondria-associated membranes, constitutes a strong apoptotic signal. Recently, PC2 was shown to be enriched at mitochondria-associated membranes. In PC2-knockdown kidney epithelial cells, collecting duct-specific Pc2knockdown mice, and cyst-lining epithelial cells from human ADPKD kidneys, the expression of the ER-mitochondrial tethering protein mitofusin 2 , an outer mitochondrial membrane GTPase, is enhanced, and the ER to mitochondria $\mathrm{Ca}^{2+}$ transfer is increased. ${ }^{58}$ Thus, $\mathrm{PC} 2$ also acts as a checkpoint for ER-mediated mitochondrial $\mathrm{Ca}^{2+}$ signaling, and loss of this regulation may contribute to $\mathrm{ADPKD}$.

\section{I/R-Induced Acute Kidney Injury and Intracellular Calcium Imbalance}

Acute kidney injury is estimated to account for 2 million deaths worldwide each year and is a growing global health concern. ${ }^{59}$ It has become clear that an episode of acute kidney injury is associated with an increased risk for chronic kidney disease, as well as for both short- and long-term mortality in children. ${ }^{60}$ Renal I/R injury after hypotension due to various clinical problems is the leading cause of acute kidney injury in both native and transplanted kidneys.

Renal ischemia causes the accumulation of massive unfolded and misfolded proteins in the ER of renal tubular cells due to cellular ATP depletion and changes in $\mathrm{Ca}^{2+}$ homeostasis. ${ }^{61,62}$ The high-energy demand of proximal tubular cells makes them especially vulnerable to ischemia. In a rat model of renal I/R injury, Szebenyi et $\mathrm{al}^{63}$ demonstrated that renal ischemia caused a rapid and transient increase in cytoplasmic $\mathrm{Ca}^{2+}$ levels in proximal tubular cells, which returned to the basal level before the end of the ischemic period. Notably, reperfusion led to a secondary proximal tubular $\mathrm{Ca}^{2+}$ load, which was significantly decreased by a specific and potent blocker of $\mathrm{Na}-\mathrm{Ca}$ exchanger (Ncx1), KB-R7943.

NCX1 is a plasma membrane anti-transporter that is also located in mitochondrial and ER membrane. In normal tubular cells, it uses ATP that is stored in the electrochemical gradient of $\mathrm{Na}^{+}$by allowing $\mathrm{Na}^{+}$to flow down its gradient across the plasma membrane in exchange for intracellular $\mathrm{Ca}^{2+}$ extrusion. In contrast, in ischemic tubular cells, the intracellular $\mathrm{Na}^{+}$concentration rises from inhibition of the $\mathrm{Na}^{+} / \mathrm{K}^{+}$ATPase activity due to decreased ATP production, and activation of the $\mathrm{Na}^{+} / \mathrm{H}^{+}$exchanger due to intracellular acidosis. In turn, reperfusion may cause a large $\mathrm{Ca}^{2+}$ influx because of the reverse mode of the NCX1. ${ }^{64}$ Yamashita et $\mathrm{al}^{64}$ showed that $\mathrm{NCX}^{+/-}$mice were more resistant to I/R-caused kidney injury compared with wildtype mice. Meanwhile, $\mathrm{Ca}^{2+}$ deposition in necrotic tubular epithelium was less marked in heterozygous mice than in wild-type mice. In addition, both pre- and postischemic treatments with the NCX1 inhibitor KB-R7943 attenuated I/ R-induced renal injury, suggesting that NCX1 is a potential therapeutic target in I/R injury.

Renal tubular $\mathrm{Ca}^{2+}$ homeostasis is also fine-tuned by ER $\mathrm{Ca}^{2+}$ channels, pumps, and $\mathrm{Ca}^{2+}$-binding proteins. ${ }^{3,5}$ It has been reported that with hypoxia induced by 6 hours of exposure to $8 \%$ oxygen, mRNA levels of $\mathrm{IP}_{3} \mathrm{R} 1$ and RyR2 in mouse kidneys were increased. ${ }^{65}$ Furthermore, a study in a rat model reported that with pretreatment with an $\mathrm{IP}_{3} \mathrm{R}$ blocker, 8-(N,N-diethylamino)octyl-3,4,5-trimethoxybenzoate (TMB-8), but not with the RyR2 inhibitor dantrolene, 15 minutes before renal ischemia ${ }^{66}$ kidney function and findings on histologic examination were improved. In vitro, with TMB-8, but not dantrolene, cytosolic $\mathrm{Ca}^{2+}$ elevation and tubular cell apoptosis were significantly suppressed during antimycin $\mathrm{A}$-induced chemical anoxia.

Using biochemical assays, it has been shown that $\mathrm{IP}_{3} \mathrm{R} 1$ is physically associated with the carboxy terminus of ERlocalized PC2, and that $\mathrm{IP}_{3} \mathrm{R}$-mediated intracellular $\mathrm{Ca}^{2+}$ signaling is modulated by PC2 ${ }^{67}$ Interestingly, it has been reported that $\mathrm{Pc}^{+/-}$mouse kidneys are more sensitive to $\mathrm{I} /$ $\mathrm{R}$ injury, followed by enhanced tubular and interstitial 
proliferation, tubular apoptosis, inflammation, as well as interstitial fibrosis after $\mathrm{I} / \mathrm{R}$ surgery. ${ }^{68}$ These effects might be attributable to misregulated intracellular $\mathrm{Ca}^{2+}$ signaling stemming from altered activity levels of $\mathrm{PC} 2$ and $\mathrm{IP}_{3} \mathrm{R} 1$, which was not examined in the study. ${ }^{68}$

$\mathrm{BiP}$, the activity of which is induced in mouse kidney after bilateral I/R injury, is also an essential player in the modulation of $\mathrm{ER} \mathrm{Ca}^{2+}$ homeostasis and $\mathrm{Ca}^{2+}$-related signal transduction. ${ }^{69} \mathrm{BiP}$ has been associated with the highly conserved ER chaperone protein sigma-1 receptor (Sig-1R) at the ER-mitochondrial contact sites, mitochondria-associated membranes. When excessive $\mathrm{Ca}^{2+}$ is released from the ER, Sig-1R is dissociated from $\mathrm{BiP}$ and binds to $\mathrm{IP}_{3} \mathrm{R} 3$, which attenuates $\mathrm{IP}_{3} \mathrm{R} 3$ degradation, stabilizes $\mathrm{IP}_{3} \mathrm{R} 3$ at mitochondria-associated membranes, and prolongs $\mathrm{Ca}^{2+}$ signaling to the mitochondria. ${ }^{70}$ It has been reported in a rat model that pretreatment with fluvoxamine, a Sig-1R agonist, improved survival and renal function, as well as ameliorated renal inflammatory response after renal I/R injury via Aktmediated nitric oxide signaling and increased peritubular vasodilation and renal perfusion. ${ }^{71}$ However, the role of ER or mitochondrial $\mathrm{Ca}^{2+}$ homeostasis in this rat $\mathrm{I} / \mathrm{R}$ injury model was not checked. Additionally, $\mathrm{BiP}$ regulates $\mathrm{ER} \mathrm{Ca}^{2+}$ homeostasis by closing the Sec61 channel during protein translocation. The Sec61 translocon of the ER membrane forms an aqueous pore that mediates controlled ER $\mathrm{Ca}^{2+}$ efflux during protein translocation. Moreover, to seal the translocon, BiP must assume the ADP-bound conformation, and reopening of the pore requires an ATP binding-induced conformational change. ${ }^{72}$ Functions of these ER $\mathrm{Ca}^{2+}$-binding proteins further support the crucial role of $\mathrm{Ca}^{2+}$ in the pathogenesis of renal I/R injury.

\section{Conclusion}

$\mathrm{Ca}^{2+}$ fluctuation and homeostasis in the ER, the largest intracellular $\mathrm{Ca}^{2+}$ store, are implicated in a myriad of coordinated cellular processes, including protein folding and secretion, post-translational modification, and lipid and sterol biosynthesis. Modulation of ER $\mathrm{Ca}^{2+}$ pumps, channels, and $\mathrm{Ca}^{2+}$-binding proteins is tightly controlled at the molecular level to affect ER $\mathrm{Ca}^{2+}$ stores, signaling, and interorganelle communication. Disturbed ER $\mathrm{Ca}^{2+}$ balance affects cell function and survival in a variety of kidney diseases. Understanding the ER $\mathrm{Ca}^{2+}$-handling molecular mechanism and regulation, in combination with the precision intracellular delivery of ER modulators based on novel nanoplatforms, will change the therapeutic landscape for kidney disease.

\section{References}

1. La Rovere RM, Roest G, Bultynck G, Parys JB: Intracellular Ca(2+) signaling and $\mathrm{Ca}(2+)$ microdomains in the control of cell survival, apoptosis and autophagy. Cell Calcium 2016, 60:74-87
2. Mekahli D, Bultynck G, Parys JB, De Smedt H, Missiaen L: Endoplasmic-reticulum calcium depletion and disease. Cold Spring Harb Perspect Biol 2011, 3:a004317

3. Carreras-Sureda A, Pihan P, Hetz C: Calcium signaling at the endoplasmic reticulum: fine-tuning stress responses. Cell Calcium 2018, 70:24-31

4. Arruda AP, Hotamisligil GS: Calcium homeostasis and organelle function in the pathogenesis of obesity and diabetes. Cell Metab 2015, 22:381-397

5. Krebs J, Agellon LB, Michalak M: $\mathrm{Ca}(2+)$ homeostasis and endoplasmic reticulum (ER) stress: an integrated view of calcium signaling. Biochem Biophys Res Commun 2015, 460:114-121

6. Corazzari M, Gagliardi M, Fimia GM, Piacentini M: Endoplasmic reticulum stress, unfolded protein response, and cancer cell fate. Front Oncol 2017, 7:78

7. Zhang L, Wang A: Virus-induced ER stress and the unfolded protein response. Front Plant Sci 2012, 3:293

8. Bahar E, Kim H, Yoon H: ER stress-mediated signaling: action potential and $\mathrm{Ca}(2+)$ as key players. Int J Mol Sci 2016, 17:1558

9. Bagur R, Hajnoczky G: Intracellular $\mathrm{Ca}(2+)$ sensing: its role in calcium homeostasis and signaling. Mol Cell 2017, 66:780-788

10. Periasamy M, Kalyanasundaram A: SERCA pump isoforms: their role in calcium transport and disease. Muscle Nerve 2007, 35 : 430-442

11. Roderick HL, Lechleiter JD, Camacho P: Cytosolic phosphorylation of calnexin controls intracellular $\mathrm{Ca}(2+)$ oscillations via an interaction with SERCA2b. J Cell Biol 2000, 149:1235-1248

12. Ihara Y, Kageyama K, Kondo T: Overexpression of calreticulin sensitizes SERCA2a to oxidative stress. Biochem Biophys Res Commun 2005, 329:1343-1349

13. Kiviluoto S, Vervliet T, Ivanova H, Decuypere JP, De Smedt H, Missiaen L, Bultynck G, Parys JB: Regulation of inositol 1,4,5trisphosphate receptors during endoplasmic reticulum stress. Biochim Biophys Acta 2013, 1833:1612-1624

14. Santulli G, Nakashima R, Yuan Q, Marks AR: Intracellular calcium release channels: an update. J Physiol 2017, 595:3041-3051

15. Higo $T$, Hattori $M$, Nakamura $T$, Natsume $T$, Michikawa $T$, Mikoshiba K: Subtype-specific and ER luminal environmentdependent regulation of inositol 1,4,5-trisphosphate receptor type 1 by ERp44. Cell 2005, 120:85-98

16. Lanner JT, Georgiou DK, Joshi AD, Hamilton SL: Ryanodine receptors: structure, expression, molecular details, and function in calcium release. Cold Spring Harb Perspect Biol 2010, 2:a003996

17. Ruiz A, Matute C, Alberdi E: Endoplasmic reticulum $\mathrm{Ca}(2+)$ release through ryanodine and $\mathrm{IP}(3)$ receptors contributes to neuronal excitotoxicity. Cell Calcium 2009, 46:273-281

18. Niggli E, Ullrich ND, Gutierrez D, Kyrychenko S, Polakova E, Shirokova N: Posttranslational modifications of cardiac ryanodine receptors: $\mathrm{Ca}(2+)$ signaling and EC-coupling. Biochim Biophys Acta 2013, 1833:866-875

19. Andersson DC, Betzenhauser MJ, Reiken S, Umanskaya A, Shiomi T, Marks AR: Stress-induced increase in skeletal muscle force requires protein kinase A phosphorylation of the ryanodine receptor. $\mathrm{J}$ Physiol 2012, 590:6381-6387

20. Wehrens XH, Lehnart SE, Reiken S, Vest JA, Wronska A, Marks AR: Ryanodine receptor/calcium release channel PKA phosphorylation: a critical mediator of heart failure progression. Proc Natl Acad Sci U S A 2006, 103:511-518

21. Park SJ, Kim Y, Yang SM, Henderson MJ, Yang W, Lindahl M, Urano F, Chen YM: Discovery of endoplasmic reticulum calcium stabilizers to rescue ER-stressed podocytes in nephrotic syndrome. Proc Natl Acad Sci U S A 2019, 116:14154-14163

22. Wehrens XH, Lehnart SE, Reiken SR, Marks AR: Ca2+/calmodulindependent protein kinase II phosphorylation regulates the cardiac ryanodine receptor. Circ Res 2004, 94:e61-e70

23. Alonso MT, Manjarres IM, Garcia-Sancho J: Privileged coupling between $\mathrm{Ca}(2+)$ entry through plasma membrane store-operated 
$\mathrm{Ca}(2+)$ channels and the endoplasmic reticulum $\mathrm{Ca}(2+)$ pump. Mol Cell Endocrinol 2012, 353:37-44

24. Coe H, Michalak M: Calcium binding chaperones of the endoplasmic reticulum. Gen Physiol Biophys 2009, 28 Focus Issue:F96-F103

25. Prins D, Groenendyk J, Touret N, Michalak M: Modulation of STIM1 and capacitative $\mathrm{Ca} 2+$ entry by the endoplasmic reticulum luminal oxidoreductase ERp57. EMBO Rep 2011, 12:1182-1188

26. Pinton P, Giorgi C, Siviero R, Zecchini E, Rizzuto R: Calcium and apoptosis: ER-mitochondria $\mathrm{Ca} 2+$ transfer in the control of apoptosis. Oncogene 2008, 27:6407-6418

27. Orrenius S, Zhivotovsky B, Nicotera P: Regulation of cell death: the calcium-apoptosis link. Nat Rev Mol Cell Biol 2003, 4:552-565

28. Michalak M, Robert Parker JM, Opas M: Ca2+ signaling and calcium binding chaperones of the endoplasmic reticulum. Cell Calcium 2002, 32:269-278

29. Hajnoczky G, Csordas G, Das S, Garcia-Perez C, Saotome M, Sinha Roy S, Yi M: Mitochondrial calcium signalling and cell death: approaches for assessing the role of mitochondrial $\mathrm{Ca} 2+$ uptake in apoptosis. Cell Calcium 2006, 40:553-560

30. Santulli G, Xie W, Reiken SR, Marks AR: Mitochondrial calcium overload is a key determinant in heart failure. Proc Natl Acad Sci U S A 2015, 112:11389-11394

31. Feng N, Anderson ME: CaMKII is a nodal signal for multiple programmed cell death pathways in heart. J Mol Cell Cardiol 2017, 103: 102-109

32. Ozcan L, Wong CC, Li G, Xu T, Pajvani U, Park SK, Wronska A, Chen BX, Marks AR, Fukamizu A, Backs J, Singer HA, Yates JR 3rd, Accili D, Tabas I: Calcium signaling through CaMKII regulates hepatic glucose production in fasting and obesity. Cell Metab 2012, 15:739-751

33. Bissonnette SL, Haas A, Mann KK, Schlezinger JJ: The role of CaMKII in calcium-activated death pathways in bone marrow B cells. Toxicol Sci 2010, 118:108-118

34. Timmins JM, Ozcan L, Seimon TA, Li G, Malagelada C, Backs J, Backs T, Bassel-Duby R, Olson EN, Anderson ME, Tabas I: Calcium/calmodulin-dependent protein kinase II links ER stress with Fas and mitochondrial apoptosis pathways. J Clin Invest 2009, 119: 2925-2941

35. Smith MA, Schnellmann RG: Calpains, mitochondria, and apoptosis. Cardiovasc Res 2012, 96:32-37

36. Biagioli M, Pifferi S, Ragghianti M, Bucci S, Rizzuto R, Pinton P: Endoplasmic reticulum stress and alteration in calcium homeostasis are involved in cadmium-induced apoptosis. Cell Calcium 2008, 43: 184-195

37. Mandic A, Viktorsson K, Strandberg L, Heiden T, Hansson J, Linder S, Shoshan MC: Calpain-mediated Bid cleavage and calpainindependent Bak modulation: two separate pathways in cisplatininduced apoptosis. Mol Cell Biol 2002, 22:3003-3013

38. Chen YM, Liapis H: Focal segmental glomerulosclerosis: molecular genetics and targeted therapies. BMC Nephrol 2015, 16:101

39. Hasselbacher K, Wiggins RC, Matejas V, Hinkes BG, Mucha B, Hoskins BE, Ozaltin F, Nurnberg G, Becker C, Hangan D, Pohl M, Kuwertz-Broking E, Griebel M, Schumacher V, Royer-Pokora B, Bakkaloglu A, Nurnberg P, Zenker M, Hildebrandt F: Recessive missense mutations in LAMB2 expand the clinical spectrum of LAMB2-associated disorders. Kidney Int 2006, 70:1008-1012

40. Schlondorff J, Del Camino D, Carrasquillo R, Lacey V, Pollak MR: TRPC6 mutations associated with focal segmental glomerulosclerosis cause constitutive activation of NFAT-dependent transcription. Am J Physiol Cell Physiol 2009, 296:C558-C569

41. Wang Y, Jarad G, Tripathi P, Pan M, Cunningham J, Martin DR Liapis H, Miner JH, Chen F: Activation of NFAT signaling in podocytes causes glomerulosclerosis. J Am Soc Nephrol 2010, 21 $1657-1666$

42. Cardozo AK, Ortis F, Storling J, Feng YM, Rasschaert J, Tonnesen M, Van Eylen F, Mandrup-Poulsen T, Herchuelz A, Eizirik DL: Cytokines downregulate the sarcoendoplasmic reticulum pump $\mathrm{Ca} 2+$ ATPase $2 \mathrm{~b}$ and deplete endoplasmic reticulum $\mathrm{Ca} 2+$, leading to induction of endoplasmic reticulum stress in pancreatic beta-cells. Diabetes 2005, 54:452-461

43. Wold LE, Dutta K, Mason MM, Ren J, Cala SE, Schwanke ML, Davidoff AJ: Impaired SERCA function contributes to cardiomyocyte dysfunction in insulin resistant rats. J Mol Cell Cardiol 2005, 39 297-307

44. Park SW, Zhou Y, Lee J, Lee J, Ozcan U: Sarco(endo)plasmic reticulum $\mathrm{Ca} 2+-\mathrm{ATPase} 2 \mathrm{~b}$ is a major regulator of endoplasmic retic ulum stress and glucose homeostasis in obesity. Proc Natl Acad Sci U S A 2010, 107:19320-19325

45. Guo H, Cao A, Chu S, Wang Y, Zang Y, Mao X, Wang H, Wang Y, Liu C, Zhang X, Peng W: Astragaloside IV attenuates podocyte apoptosis mediated by endoplasmic reticulum stress through upregulating sarco/endoplasmic reticulum $\mathrm{Ca}(2+)$-ATPase 2 expression in diabetic nephropathy. Front Pharmacol 2016, 7:500

46. Chen S, He FF, Wang H, Fang Z, Shao N, Tian XJ, Liu JS, Zhu ZH, Wang YM, Wang S, Huang K, Zhang C: Calcium entry via TRPC6 mediates albumin overload-induced endoplasmic reticulum stress and apoptosis in podocytes. Cell Calcium 2011, 50:523-529

47. El Karoui K, Viau A, Dellis O, Bagattin A, Nguyen C, Baron W, Burtin M, Broueilh M, Heidet L, Mollet G, Druilhe A, Antignac C, Knebelmann B, Friedlander G, Bienaime F, Gallazzini M, Terzi F: Endoplasmic reticulum stress drives proteinuria-induced kidney lesions via Lipocalin 2. Nat Commun 2016, 7:10330

48. Lemos FO, Ehrlich BE: Polycystin and calcium signaling in cell death and survival. Cell Calcium 2018, 69:37-45

49. Mekahli D, Parys JB, Bultynck G, Missiaen L, De Smedt H: Polycystins and cellular Ca2+ signaling. Cell Mol Life Sci 2013, 70: 2697-2712

50. Hanaoka K, Qian F, Boletta A, Bhunia AK, Piontek K, Tsiokas L, Sukhatme VP, Guggino WB, Germino GG: Co-assembly of polycystin- 1 and -2 produces unique cation-permeable currents. $\mathrm{Na}$ ture 2000, 408:990-994

51. Nauli SM, Alenghat FJ, Luo Y, Williams E, Vassilev P, Li X, Elia AE, Lu W, Brown EM, Quinn SJ, Ingber DE, Zhou J: Polycystins 1 and 2 mediate mechanosensation in the primary cilium of kidney cells. Nat Genet 2003, 33:129-137

52. Choi YH, Suzuki A, Hajarnis S, Ma Z, Chapin HC, Caplan MJ Pontoglio M, Somlo S, Igarashi P: Polycystin-2 and phosphodiesterase $4 \mathrm{C}$ are components of a ciliary A-kinase anchoring protein complex that is disrupted in cystic kidney diseases. Proc Natl Acad Sci U S A 2011, 108:10679-10684

53. Yamaguchi T, Hempson SJ, Reif GA, Hedge AM, Wallace DP Calcium restores a normal proliferation phenotype in human polycystic kidney disease epithelial cells. J Am Soc Nephrol 2006, 17: $178-187$

54. Rees S, Kittikulsuth W, Roos K, Strait KA, Van Hoek A, Kohan DE: Adenylyl cyclase 6 deficiency ameliorates polycystic kidney disease. J Am Soc Nephrol 2014, 25:232-237

55. Szado T, Vanderheyden V, Parys JB, De Smedt H, Rietdorf K, Kotelevets L, Chastre E, Khan F, Landegren U, Soderberg O, Bootman MD, Roderick HL: Phosphorylation of inositol 1,4,5trisphosphate receptors by protein kinase B/Akt inhibits $\mathrm{Ca} 2+$ release and apoptosis. Proc Natl Acad Sci U S A 2008, 105: 2427-2432

56. Koulen P, Cai Y, Geng L, Maeda Y, Nishimura S, Witzgall R, Ehrlich BE, Somlo S: Polycystin-2 is an intracellular calcium release channel. Nat Cell Biol 2002, 4:191-197

57. Santoso NG, Cebotaru L, Guggino WB: Polycystin-1, 2, and STIM1 interact with IP(3)R to modulate ER Ca release through the PI3K/Akt pathway. Cell Physiol Biochem 2011, 27:715-726

58. Kuo IY, Brill AL, Lemos FO, Jiang JY, Falcone JL, Kimmerling EP, Cai Y, Dong K, Kaplan DL, Wallace DP, Hofer AM, Ehrlich BE: Polycystin 2 regulates mitochondrial $\mathrm{Ca}(2+)$ signaling, bioenergetics, and dynamics through mitofusin 2. Sci Signal 2019, 12:eaat7397 
59. Lewington AJ, Cerda J, Mehta RL: Raising awareness of acute kidney injury: a global perspective of a silent killer. Kidney Int 2013, 84: 457-467

60. Coca SG, Yusuf B, Shlipak MG, Garg AX, Parikh CR: Long-term risk of mortality and other adverse outcomes after acute kidney injury: a systematic review and meta-analysis. Am J Kidney Dis 2009, 53:961-973

61. Xu Y, Guo M, Jiang W, Dong H, Han Y, An XF, Zhang J: Endoplasmic reticulum stress and its effects on renal tubular cells apoptosis in ischemic acute kidney injury. Ren Fail 2016, 38:831-837

62. Yan M, Shu S, Guo C, Tang C, Dong Z: Endoplasmic reticulum stress in ischemic and nephrotoxic acute kidney injury. Ann Med 2018, 50:381-390

63. Szebenyi K, Furedi A, Kolacsek O, Csohany R, Prokai A, KisPetik K, Szabo A, Bosze Z, Bender B, Tovari J, Enyedi A, Orban TI, Apati A, Sarkadi B: Visualization of calcium dynamics in kidney proximal tubules. J Am Soc Nephrol 2015, 26:2731-2740

64. Yamashita J, Kita S, Iwamoto T, Ogata M, Takaoka M, Tazawa N, Nishikawa M, Wakimoto K, Shigekawa M, Komuro I, Matsumura Y: Attenuation of ischemia/reperfusion-induced renal injury in mice deficient in Na+/Ca2+ exchanger. J Pharmacol Exp Ther 2003, 304:284-293

65. Jurkovicova D, Sedlakova B, Lacinova L, Kopacek J, Sulova Z, Sedlak J, Krizanova O: Hypoxia differently modulates gene expression of inositol 1,4,5-trisphosphate receptors in mouse kidney and HEK 293 cell line. Ann N Y Acad Sci 2008, 1148:421-427
66. Wu D, Chen X, Ding R, Qiao X, Shi S, Xie Y, Hong Q, Feng Z: Ischemia/reperfusion induce renal tubule apoptosis by inositol 1,4,5trisphosphate receptor and L-type $\mathrm{Ca} 2+$ channel opening. Am J Nephrol 2008, 28:487-499

67. Li Y, Wright JM, Qian F, Germino GG, Guggino WB: Polycystin 2 interacts with type I inositol 1,4,5-trisphosphate receptor to modulate intracellular Ca2+ signaling. J Biol Chem 2005, 280: 41298-41306

68. Prasad S, McDaid JP, Tam FW, Haylor JL, Ong AC: Pkd2 dosage influences cellular repair responses following ischemia-reperfusion injury. Am J Pathol 2009, 175:1493-1503

69. Dudek J, Benedix J, Cappel S, Greiner M, Jalal C, Muller L, Zimmermann R: Functions and pathologies of BiP and its interaction partners. Cell Mol Life Sci 2009, 66:1556-1569

70. Hayashi T, Su TP: Sigma-1 receptor chaperones at the ERmitochondrion interface regulate $\mathrm{Ca}(2+)$ signaling and cell survival. Cell 2007, 131:596-610

71. Hosszu A, Antal Z, Lenart L, Hodrea J, Koszegi S, Balogh DB, Banki NF, Wagner L, Denes A, Hamar P, Degrell P, Vannay A, Szabo AJ, Fekete A: Sigma1-receptor agonism protects against renal ischemia-reperfusion injury. J Am Soc Nephrol 2017, 28:152-165

72. Alder NN, Shen Y, Brodsky JL, Hendershot LM, Johnson AE: The molecular mechanisms underlying BiP-mediated gating of the Sec61 translocon of the endoplasmic reticulum. J Cell Biol 2005, 168: 389-399 